\title{
A COMPREHENSIVE ELECTROMAGNETIC SIMULATION MODEL FOR SWITCHED RELUCTANCE MOTOR OPERATING UNDER MULTIPHASE EXCITATION
}

\author{
Yousuf Sohrabinasab - Babak Ganji
}

Department of Power, Electrical and Computer Engineering Faculty, University of Kashan, Kashan, Iran

\begin{tabular}{l}
\hline ARTICLE INFO \\
\hline Article history: \\
Received: 30.03 .2018$. \\
Received in revised form: 27.08 .2018$. \\
Accepted: 31.08 .2018$. \\
\hline Keywords: \\
Switched reluctance motor \\
Multiphase excitation \\
Core loss calculation \\
Finite element analysis \\
\hline DOI: http://doi.org/10.30765/er.39.3.11 \\
\end{tabular}

\section{Introduction}

Due to exclusive features of the SRM such as high reliability, simple and robustness structure, large torque/weight ratio, and appropriate operation over a wide range of speed, special attention has been paid to the SRM within the last three decades and it is used for different applications [1-5]. Most of electromagnetic models presented for the SRM are for one-phase excitation control mode while the multiphase operation is more applicable because of higher efficiency and lower torque ripple [6-7]. It is hard to present an accurate electromagnetic model for the SRM operating under multiphase excitation due to high-saturation of the motor.

\begin{abstract}
:
In the present paper, a comprehensive electromagnetic simulation model based on finite element method (FEM) is introduced for the switched reluctance motor (SRM) by which important electromagnetic characteristics are predicted for the multiphase excitation mode. The inputs of the model are the design data and control parameters and it considers different arrangements of the phase winding connections. The simulation model is developed totally in ANSYS parametric design language (APDL) as a parametric model and it can be used easily for different types of the SRM. Carrying out $2 D$ finite element transient analysis in the simulation model, flux density waveforms within the motor are predicted and a procedure is developed for core loss determination of the SRM operating under multiphase excitation. Applying the introduced simulation model to an 8/6 SRM, simulation results are presented for operation with simultaneous twophase excitation.
\end{abstract}

Using distributed saturable elements, an equivalent circuit model is described in [8] for the SRM which includes multiple-phase-at-a-time excitation. Considering mutual coupling effect between adjacent phases in the SRM, the modeling theory is presented in [9] when simultaneous excitation of two-phase windings occurs. Taking into account mutual coupling between the phases, a general nonlinear magnetic equivalent circuit model is presented in [10] for multiphase excitation of the SRM. Considering the advantages of the Miller model, they have been extended in [11] to introduce an analytical model for the SRM operating under two-phase excitation. Based on FE calculations, it is also shown that the mutual coupling between the phases has a significant influence on flux-linkage especially in

\footnotetext{
* Corresponding author.

E-mail address: bganji@kashanu.ac.ir.
} 
high levels of phase currents. A dynamic two-phase excitation model is proposed in [12] for the SRM in which the mutual coupling in the presence of magnetic saturation has been considered. Considering the mutual coupling between the phases, dynamic performances of two mutually coupled dualchannel switched reluctance machines are compared in [13]. Calculating self and mutual inductances, the mutual coupling effect on instantaneous torque is evaluated in [14]. In order to take the mutual coupling into account, a nonlinear analytical model comprising multiphase excitation is introduced in [15].

Nevertheless, some works have been reported on electromagnetic modeling of the SRM operating under multi-phase excitation. There is still needing to introduce an accurate electromagnetic model for this effective control mode. Due to completely non-linear behavior of the SRM, the FEM can be used appropriately for the performance prediction of this motor [16-19] using high speed large memory contemporary computers. Therefore, an electromagnetic simulation model based on FEM is introduced here for the SRM with multiphase excitation by which dynamic characteristics of the motor are obtained accurately from the 2D FE transient analysis of the motor. The simulation model is built up totally in APDL usable for all conventional types of the SRM. To use the model which considers the mutual saturation effect, one should only identify the design data and the motor control parameters. In the developed simulation model, a procedure is also suggested for core loss estimation because most of available core loss models have been developed for single-phase excitation [18-21], therefore they cannot be used for accurate prediction of core loss for multiphase operation. At the following, the simulation model is described in Section 2. Applying the introduced model to an 8/6 SRM, simulation results are given in Section 3. Finally, the paper is concluded in Section 4.

\section{Electromagnetic simulation model}

A comprehensive electromagnetic simulation model has been developed for the SRM with the 2D FEM using ANSYS FE package by which some important electromagnetic characteristics are predicted when several phases of the motor are simultaneously excited. The predicted characteristics consist of the phase current waveform, instantaneous torque waveform, flux density waveforms in different parts of the magnetic circuit, copper losses, core loss, and efficiency. The inputs of the simulation model created fully in APDL are the design data and control parameters including turn-on angle, turn-off angle, motor speed, and the phase voltage. Different parts of the simulation model are described briefly in the following.

\subsection{Motor analysis}

To analyze the SRM using ANSYS, the geometric structure of the machine must be plotted first. Because the SRM has a complicated structure as observed in Fig. 1 for an 8/6 SRM, this task is timeconsuming and hard each time before the analysis. Therefore, the geometric structure of the SRM is created as a parametric model in the FE model and some important design parameters are selected as the geometrical parameters. In order to determine the dynamic characteristics of the SRM using ANSYS, the FE model should be coupled to the external electric circuit and the time-stepping analysis must be carried out as well. To have a convergent solution when the developed simulation model is used for different operating points, how to mesh the air-gap area in the FE model is important. More details about the parametric geometrical model, the manner of meshing, and analysis are available in $[16,18]$.

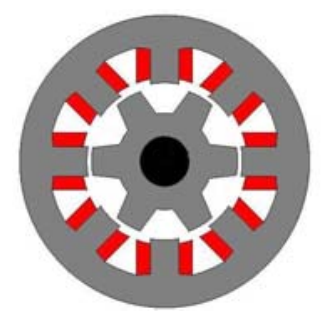

Figure 1. The geometrical model of the 8/6 SRM.

\subsection{Core loss estimation}

When carrying out the 2D FE transient analysis in the developed electromagnetic simulation model, it is possible to predict the instantaneous flux waveforms in different parts of the motor including stator poles, stator core, rotor poles, and rotor core. To do this, some areas are considered in the FE model for different parts of the SRM and the flux passing them is calculated and stored in each time step [16]. The flux density waveform in each part is then derived from dividing the amplitude of the instantaneous flux predicted for that part by the related area. Once the flux density waveforms in different parts of SRM are 
known, the corresponding core loss is calculated from the improved Steinmetz equation [18]:

$$
P_{\mathrm{c}}=K_{\mathrm{cf}} C_{\mathrm{h}} f B_{\text {max }}^{a+b B_{\text {max }}}+\frac{1}{2 \pi^{2}} C_{\mathrm{e}}\left(\frac{d B}{d t}\right)_{\text {avg }}^{2}
$$

where $f$ is the frequency, $B_{\max }$ is the maximum flux density, $a, b, C_{\mathrm{h}}$ and $C_{\mathrm{e}}$ are the Steinmetz parameters and $K_{\mathrm{cf}}$ is the modification coefficient for considering the hysteresis loss related to minor loops.

\subsection{Other important characteristics}

Since instantaneous torque and phase current waveforms are predicted in the developed simulation model, torque ripple and copper losses can be calculated easily as follows:

$$
\begin{gathered}
\text { Torque ripple }[\%]=\frac{T_{\max }-T_{\min }}{T_{\mathrm{avg}}} \cdot 100 \\
P_{\mathrm{cu}}=m R I_{\mathrm{rmsh}}^{2}
\end{gathered}
$$

where $T_{\max }, T_{\min }$ are maximum and minimum torque and $T_{\text {avg. }}$ is average torque, $m$ is the numbers of phases, $R$ is phase resistance and $I_{\mathrm{rms}}$ is root mean square of phase current. Having the average torque, copper losses, and core loss in the developed simulation model, efficiency is derived from equation below:

$$
\eta[\%]=\frac{T_{\text {avg }} \omega_{\mathrm{m}}}{T_{\mathrm{avg}} \omega_{\mathrm{m}}+P_{\mathrm{cu}}+P_{\mathrm{c}}} \cdot 100
$$

where $\omega_{\mathrm{m}}$ is rotor speed and $P_{\mathrm{c}}$ is the estimated core loss.

\section{Simulation results}

Applying the electromagnetic simulation model to an 8/6 SRM, $1 \mathrm{~kW}, 93 \mathrm{~V}, 1500 \mathrm{rpm}$ with specifications given in Table 1, the simulation results including phase current waveform, instantaneous torque, flux density waveforms, and related core loss in different parts of the motor are presented here when two phases are excited simultaneously. To produce the maximum torque in two-phase excitation mode of the 8/6 SRM, the ideal phase current waveforms are shown in Fig. 2. Since the SRM is a voltage-fed machine, the simulation model is developed in such manner that value of the phase voltage is identified as input. Therefore, the current regulation control mode with a narrow hysteresis band $(0.1 \mathrm{~A})$ is considered to simulate the current pulses depicted in Fig. 2. The simulated phase current waveforms for the discussed 8/6 SRM in the rated speed are shown in Fig. 3 and all simulation results given in this paper are related to this operating point. Using the developed simulation model, the instantaneous torque is predicted for this considered operating point and it is illustrated in Fig. 4. Having the predicted torque waveform, average torque is $2.79 \mathrm{Nm}$ and torque ripple derived from (3) is $79.5 \%$. To predict the instantaneous torque, the computation time is around 20 minutes on a 2.70 $\mathrm{GHz}$ Intel Core(TM) i7 with 8GB RAM.

Table 1. Motor specifications [18]

\begin{tabular}{|l|r|}
\hline Stator outer diameter [mm] & 125 \\
\hline Stator slot-bottom diameter [mm] & 100 \\
\hline Rotor outer diameter [mm] & 63 \\
\hline Rotor slot-bottom diameter [mm] & 41 \\
\hline Air gap length [mm] & 0.35 \\
\hline Shaft diameter [mm] & 21 \\
\hline Stack length [mm] & 90 \\
\hline Stator pole arc [deg.] & 21 \\
\hline Rotor pole arc [deg.] & 21 \\
\hline Turns per coil & 124 \\
\hline Resistance @ $20^{\circ} \mathrm{C}[\mathrm{ohm}]$ & 0.69 \\
\hline
\end{tabular}

\subsection{Influence of the mutual coupling on instantaneous torque}

It is conventional to determine the instantaneous torque of the SRM using the predicted instantaneous torque produced by one phase through superposition rule. In comparison with the developed simulation model, this method has higher computation speed, but it ignores the coupling effect between phases. Carrying out the 2D FE transient analysis of the discussed 8/6 SRM when one phase of the motor is only excited, an instantaneous torque waveform is derived from this method for the considered operating point and it is compared in Fig. 5 with that predicted using the simulation model. For this torque waveform, the average torque and torque ripple are $2.92 \mathrm{Nm}$ and $55 \%$, respectively. This comparison shows obviously that the coupling effect must be considered for accurate determination of the 
instantaneous torque. Obtaining the self and mutual inductances for the discussed 8/6 SRM based on the FEM, mutual coupling effect on the instantaneous torque is also evaluated elaborately in [14] using the well-known analytical method.

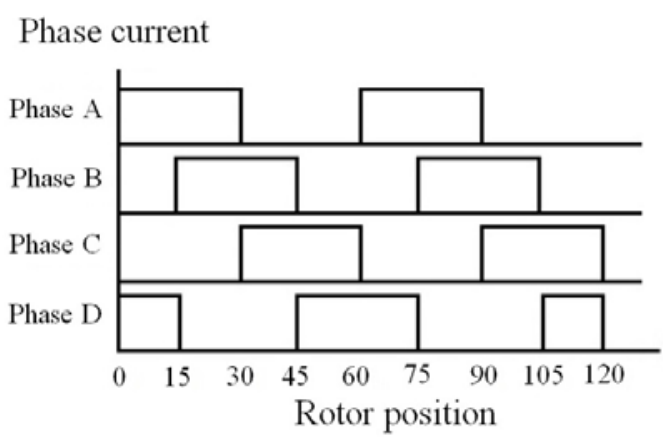

Figure 2. Excitation sequence for the 8/6 SRM [9].
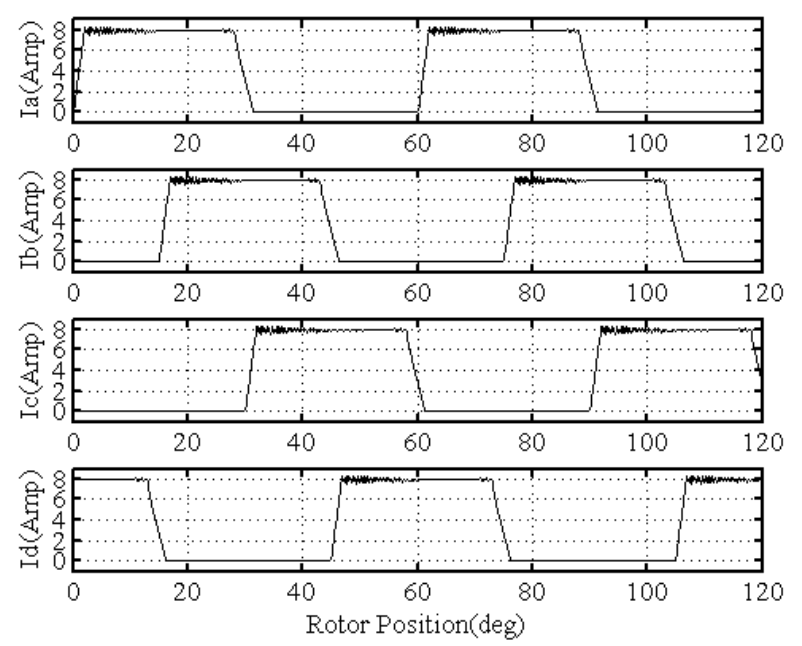

Figure 3. Simulated phase current waveforms.

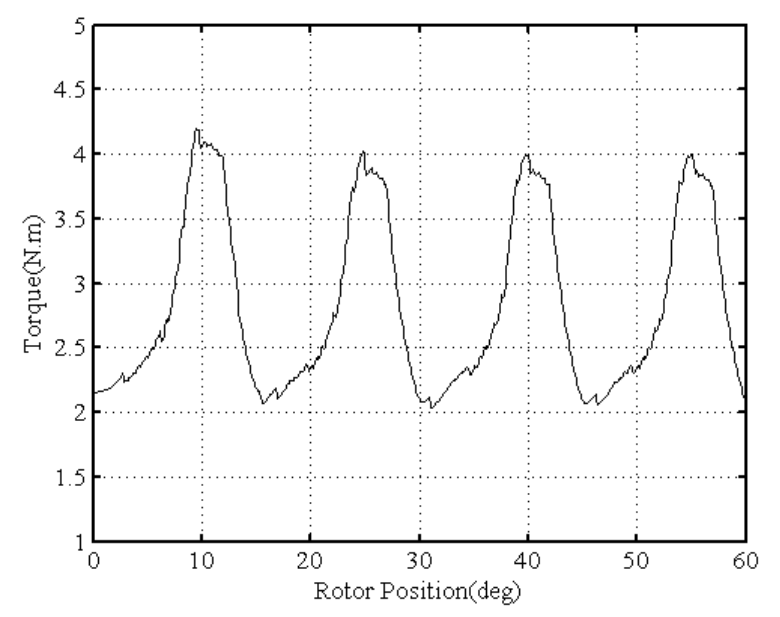

Figure 4. Predicted instantaneous torque.

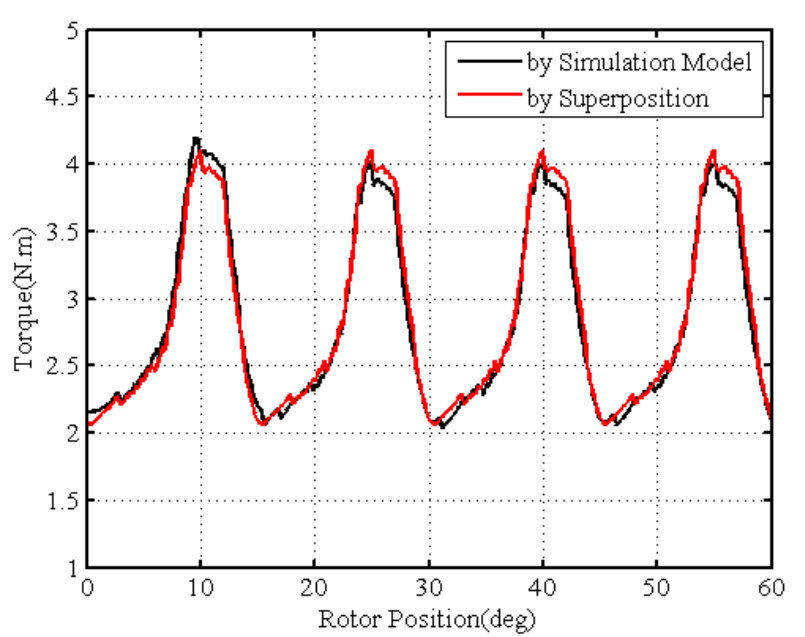

Figure 5. Instantaneous torque waveforms derived from different methods.

\subsection{Core loss estimation}

The flux density waveforms in various parts of the SRM are predicted using the developed simulation model and the core loss for the predicted flux density waveforms is derived from (1) when the Steinmetz parameters are known. These parameters for core sheets of the discussed 8/6 SRM (M 800-50A with $0.5 \mathrm{~mm}$ thickness) over the frequency range 50-200 $\mathrm{Hz}$ have been already determined in [18] and they are: $C_{\mathrm{h}}=0.0437, a=1.34, b=0.54, C_{\mathrm{e}}=0.0002$. For the considered operating point, the obtained rotor core flux density waveform is illustrated in Fig. 6 and the estimated core loss data are summarized in Table 2. As it is obviously illustrated from the simulation results, the flux waveforms in the SRM are nonsinusoidal waveforms and the core loss in stator core is larger due to higher mass and frequency.

Ignoring the coupling effect, the flux density waveforms can be obtained from the stator pole flux density waveform through superposition [18]. Carrying out the 2D FE transient analysis of the discussed 8/6 SRM when only one phase is excited, stator pole flux density waveform is predicted for the considered operating point and it is used to determine the flux density waveforms in other parts of the motor. For instance, rotor core flux density waveform obtained by this method is shown in Fig. 7. Once core loss is calculated using (1) for the flux density waveforms derived from superposition, a value of 88.7 W is obtained which is larger than that calculated from the developed simulation model $(77.9 \mathrm{~W})$. 


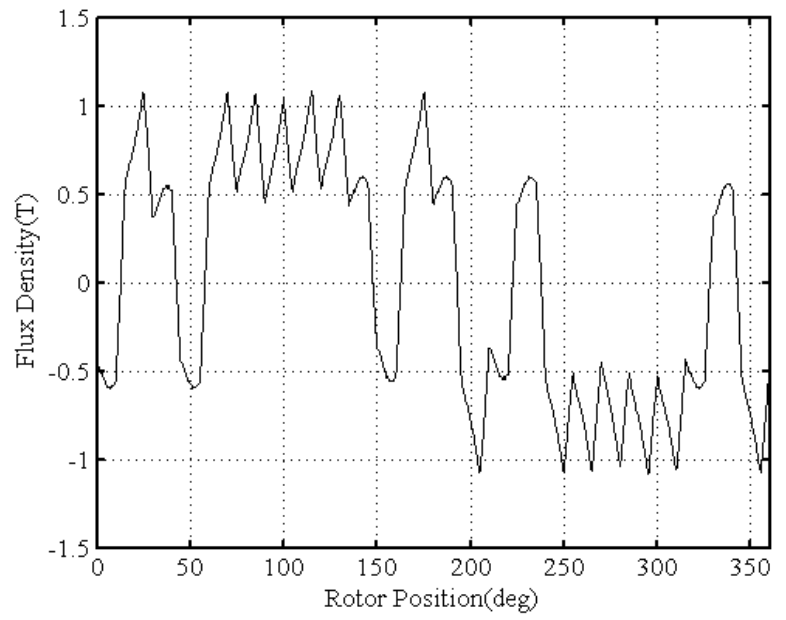

Figure 6. Predicted rotor core flux density waveform.

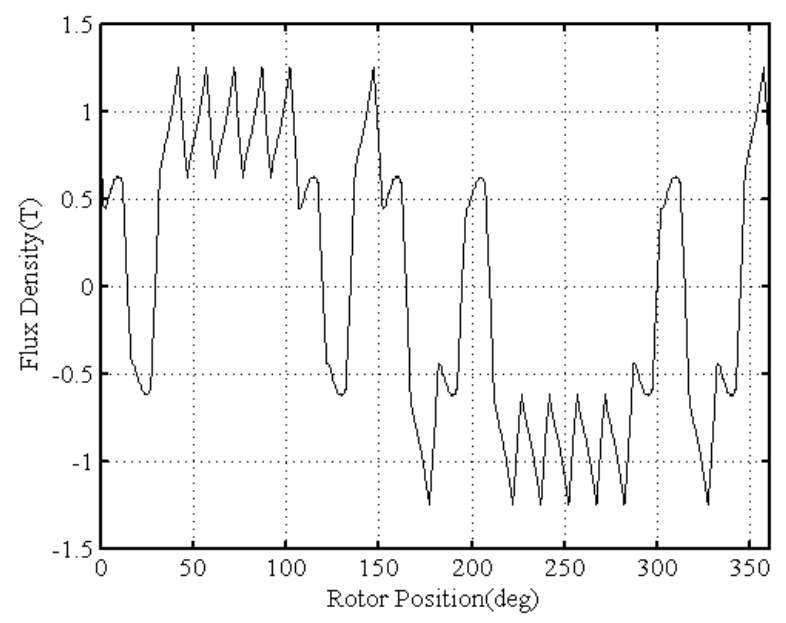

Figure 7. Rotor core flux density waveform obtained from superposition.

\subsection{Influence of geometric parameters on motor performance}

Since the electromagnetic model is created as a parametric simulation model, it is possible easily to evaluate influence of geometric parameters of the discussed 8/6 SRM on the motor performance when two phases are excited simultaneously. Changing some geometric parameters, the 2D FE transient analysis of the discussed 8/6 SRM is carried out for the considered operating point and efficiency is calculated using (4) for each design. Impact of these geometric parameters on efficiency is shown in Fig. 8 and it is obvious that axial length and pole arcs are the most important parameters. In order to keep the other parameters constant, an increase of stator core thickness and stator pole height has been modelled by boasting the outer diameter of the motor.

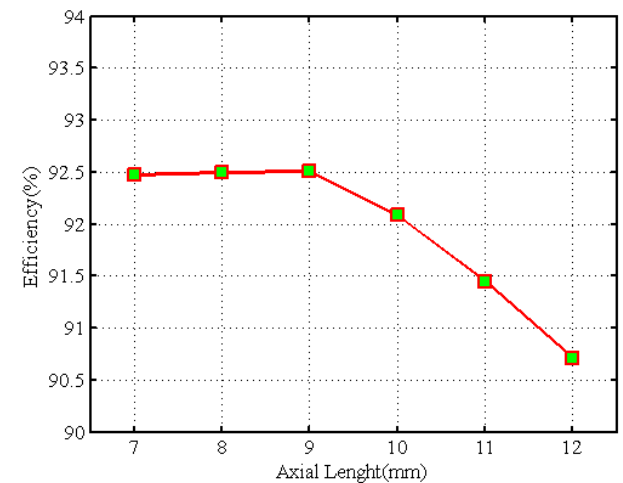

(a)

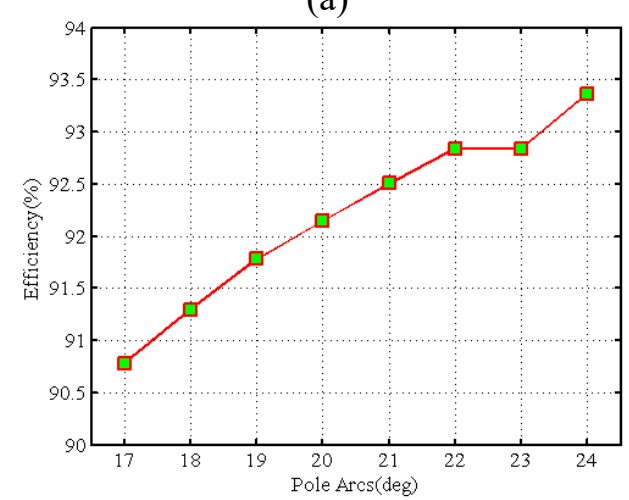

(b)

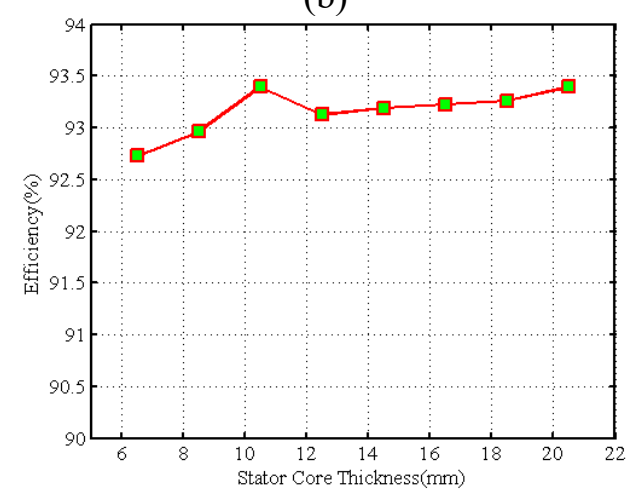

(c)

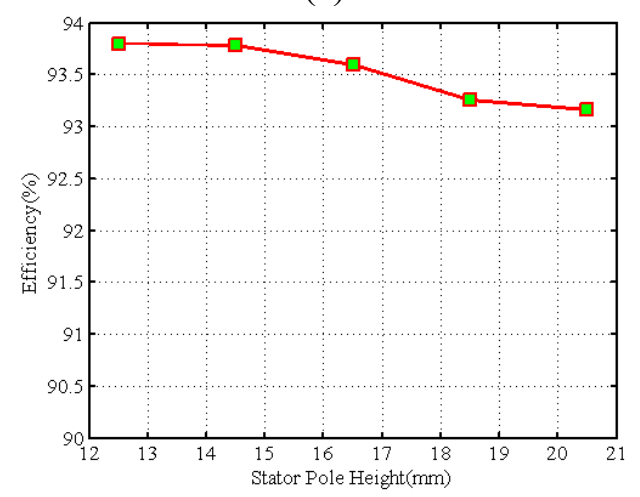

(d)

Figure 8. Variations of efficiency versus design parameters: (a) axial length, (b) pole arcs, (c) stator core thickness, (d) stator pole height. 
Table 2. Cacluated core loss

\begin{tabular}{|c|c|c|}
\hline & $\begin{array}{c}\text { Hysteresis loss } \\
{[\mathrm{W}]}\end{array}$ & $\begin{array}{c}\text { Eddy current } \\
\text { losses [W] }\end{array}$ \\
\hline Stator pole & 11.5 & 10.7 \\
\hline Stator core & 15.3 & 20.5 \\
\hline Rotor poles & 4.3 & 5.1 \\
\hline Rotor core & 4.7 & 5.8 \\
\hline Core loss & \multicolumn{2}{|c|}{77.9} \\
\hline
\end{tabular}

\subsection{The impact of the winding connections on motor performance}

The two possibilities are usually proposed for the winding connections in the 8/6 SRM shown in Fig. 9 whose corresponding arrangements of stator magnetic polarity are NNNNSSSS and NSNSSNSN, respectively. It must be noted that the winding arrangement of the discussed $8 / 6 \mathrm{SRM}$ is that depicted in Fig. 9a and all simulation results presented before are for this arrangement. Since the developed simulation model is capable to simulate the two above-mentioned winding arrangements, the motor is analyzed for the considered operating point when the winding arrangement given in Fig. 9b is modelled. The instantaneous torque waveform for this arrangement is predicted and compared to that obtained for the discussed 8/6 SRM in Fig. 10. Amplitude of the instantaneous torque for discussed 8/6 SRM is higher for the first quarter of the curve because simultaneously excitation of phases A and D causes increase of air-gap flux density. Similarly, the produced torque in the first quarter of the torque waveform is smaller for the winding connection with NSNSSNSN polarity due to reduction of flux density during excitation of these phases. For the torque waveform related to NSNSSNSN polarity, the average torque is $2.88 \mathrm{Nm}$ and torque ripple is $77.4 \%$. The core loss calculated for the motor with the winding arrangement depicted in Fig. 9(b) is $68.5 \mathrm{~W}$ and it is lower than that obtained for the discussed $8 / 6$ SRM (77.9 W) due to its smaller flux paths.

\section{Conclusion}

A comprehensive electromagnetic simulation model was introduced for the SRM with multiphase excitation by which important characteristics including instantaneous torque, average torque, torque ripple, phase current waveform, copper losses, core loss, and efficiency were predicted precisely. To use the simulation model which is fully developed in the ANSYS parametric design language, one should identify the design data along with the control parameters including turn-on and off angles, speed and phase voltage. The flux

density waveforms within the motor, which are difficult to be determined for a multiphase operation of the SRM due to high saturation, are predicted accurately in the developed simulation model and corresponding core loss different parts of the magnetic circuit of the machine is calculated using the improved Steinmetz equation.

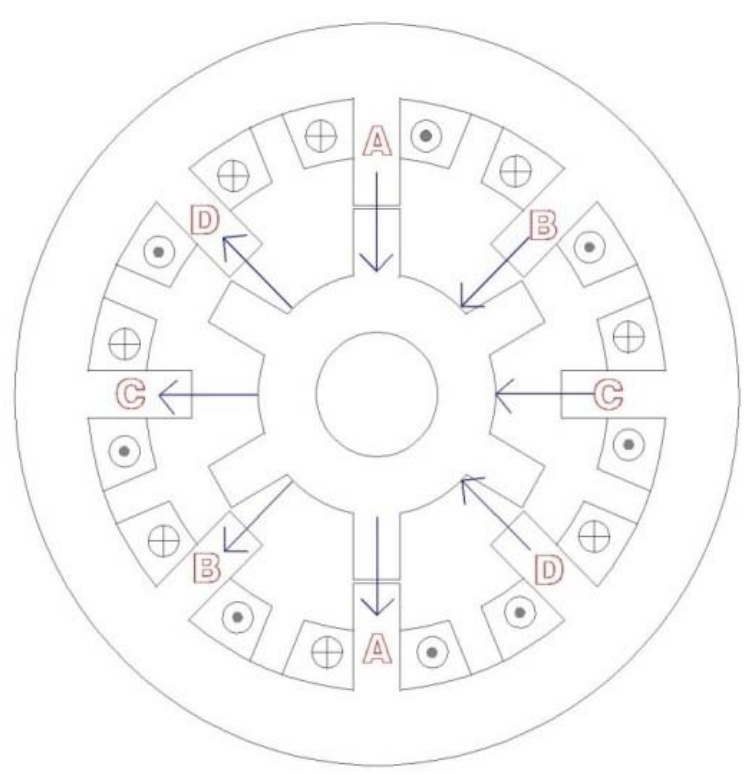

(a)

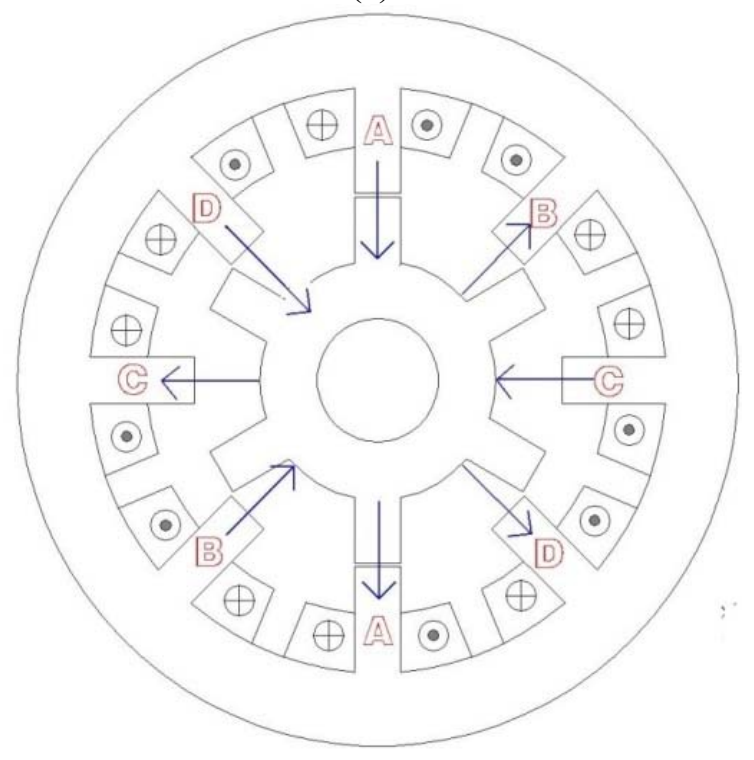

(b)

Figure 9. Winding connections proposed for the $8 / 6$ SRM: (a) NNNNSSSS, (b) NSNSSNSN. 


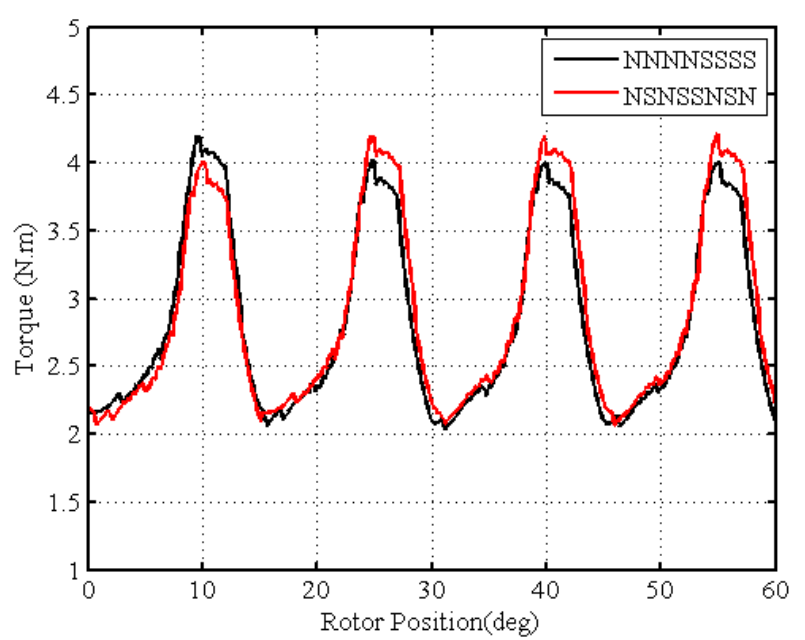

Figure 10. Instantaneous torque predicted for different winding connections.

Applying the developed simulation model to a typical 8/6 SRM with two phases simultaneously excited, the simulation results included instantaneous torque and core loss. They were compared to those determined through the superposition method where motor analysis is done based on a single-phase excitation. Significant difference between the results obtained from this comparison ( $4.6 \%$ for average torque, $30 \%$ for torque ripple and $14 \%$ for core loss) showed that the mutual coupling effect must be considered for accurate prediction of the motor performance. In addition, it was noticed with the considered operating point that changing the winding connections caused $12 \%$ reduction of core loss, while the average torque was almost constant. Furthermore, some geometric parameters of discussed 8/6 SRM were changed, and it was illustrated that axial length and pole arcs were the most effective parameters on efficiency for the considered operating point. As for a future work, the presented simulation model could be extended to consider thermal and noise because ANSYS simulates these physical environments. Furtheremore, it will be utilized appropriately for the optimal design of the SRMs with a multiphase excitation.

\section{References}

[1] Todd, R., Valdivia, V., Bryan, F. J., Barrado, A., Lázaro, A., Forsyth, A. J.: Behavioural modelling of a switched reluctance motor drive for aircraft power systems, IET Electr. Syst. Transp., 4 (2014), 4, 107-113.
[2] Lin, J., Schofield, N., Emadi, A.: External-rotor 6-10 switched reluctance motor for an electric bicycle, IEEE Trans. Transport. Electrific., 1 (2015), 4, 348-356.

[3] Zhu, J., Cheng, K. W. E., Xue, X., Zou, Y.: Design of a new enhanced torque in-wheel switched reluctance motor with divided teeth for electric vehicles, IEEE Trans. Magn., 53 (2017), 11, Article Number: 2501504.

[4] Koreboina, V. B., Narasimharaju, B. L., Vinod Kumar, D. M.: Performance investigation of simplified PWM MPPT approach for direct $P V$ fed switched reluctance motor in water pumping system, IET Electr. Power Appl., 11 (2017), 9, 1645-55.

[5] Li, Q., Liao, S.: Design of a distributed switched reluctance motor for a tip-driven fan, Engineering Review, 37 (2017), 3, 243-256.

[6] Ahn, J., Oh, S., Moon, J., Hwang, Y.: A threephase switched reluctance motor with twophase excitation, IEEE Trans. Ind. Appl., 35 (1999), 5, 1067-75.

[7] Brauer, H. J., Hennen, M. D., DeDoncker, R. $\mathrm{W}$.: Control for polyphase switched reluctance machines to minimize torque ripple and decrease ohmic machine losses, IEEE Trans. Power Electron., 27 (2012), 1, 370-78.

[8] Preston, M. A., Lyons, J. P.: A switched reluctance motor model with mutual coupling and multi-phase excitation, IEEE Trans. Magn., 27 (1991), 6, 5423-25.

[9] Michaelides, A. M., Pollock, C.: Modelling and design of switched reluctance motors with two phases simultaneously excited, IET Electr. Power Appl., 143 (1996), 5, 361-370.

[10] Deihimi, A., Farhangi, S., Henneberger, G.: $A$ general nonlinear model of switched reluctance motor with mutual coupling and multiphase excitation, Electrical Engineering, 84 (2002), 143-158.

[11] Farshad, M., Faiz, J., Lucas, C.: Development of analytical model of switched reluctance motor in two-phase excitation mode: extended Miller model, IEEE Trans. Magn., 41 (2005), 6, 21452155.

[12] Jain, A. K., Mohan, N.: Dynamic modelling, experimental characterization and verification for SRM operation with simultaneous two-phase excitation, IEEE Trans. Ind. Electron., 53 (2006), 4, 1238-49.

[13] Ding, W., Liu, L., Lou, J., Liu, Y.: Comparative studies on mutually coupled dual-channel switched reluctance machines with different 
winding connections, IEEE Trans. Magn., 49 (2013), 11, 5574-89.

[14] Ganji, B., Sohrabinasab, Y., Beigi, M.: Mutual Coupling Effect on Steady State Performance of Switched Reluctance Motor, Iranian Conference on Electrical Engineering, Tehran, Iran, 2017, 1291-95.

[15] Mihic, D. S., Terzic, M. V., Vukosavic, S. N.: A new nonlinear analytical model of the SRM with included multiphase coupling, IEEE Trans. Energy Convers., 32 (2017), 4, 1322-34.

[16] Ganji, B., Faiz, J., Kasper, K., Carstensen, C. E., DeDoncker, R. W.: Core loss model based on finite element method for switched reluctance motors, IET Electr. Power Appl., 4 (2010), 7 , 569-577.

[17] Naderi, O., Ganji, B.: Design optimization of switched reluctance motor for noise reduction, Engineering Review, 36 (2016), 3, 293-301.
[18] Faiz, J., Ganji, B., Carstensen, C. E., DeDoncker, R. W.: Loss prediction in switched reluctance motors using finite element method, J. Euro. Trans. Electr. Power., 19 (2009), 731748.

[19] Parsapoura, A., Mirzaeian, B., Moallem, M.: Predicting core losses and efficiency of SRM in continuous current mode of operation using improved analytical technique, J. Magn. Magn. Mater., 378 (2015), 118-27.

[20] Ganji, B., Mansourkiaee, Z., Faiz, J.: A fast general core loss model for switched reluctance machine, Energy, 89 (2015), 100-105.

[21] Chen, L., Chen, H., Yan, W.: A fast iron loss calculation model for switched reluctance motors, IET Electr. Power Appl., 11 (2017), 3, 478-486. 